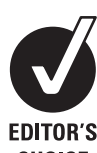

CHOICE

${ }^{1}$ Indiana University School of Medicine, Department of Ophthalmology, Section of

Pediatric Ophthalmology and Strabismus, Indianapolis, Indiana, USA; ${ }^{2}$ Korea University College of Medicine, Department of Ophthalmology, Section of Pediatric Ophthalmology and Strabismus, Ansan, Republic of Korea

Correspondence to: Dr D A Plager, 702 Rotary Circle, Indianapolis, IN 46202, USA; dplager@iupui.edu

Accepted 25 August 2008 Published Online First 27 November 2008

\title{
Stereopsis in children with unilateral pseudophakia
}

\author{
S-H Kim, ${ }^{1,2}$ D A Plager ${ }^{1}$
}

\section{ABSTRACT}

Aim: To evaluate stereoacuity and the factors that can influence stereopsis in children with unilateral pseudophakia.

Methods: Charts of 38 patients who were diagnosed as having unilateral cataract and underwent cataract extraction with primary intraocular lens implantation were retrospectively reviewed. Data were collected on gender, age, race, age at presentation and the surgery, cataract types, the presence of strabismus before and after cataract extraction, refractive error and the presence of anisometropia, best corrected visual acuity (VA) of both eyes and stereoacuity.

Results: Thirty-eight patients were divided into two groups. Group I had 21 patients whose stereopsis was better than $400 \mathrm{~s}$ of arc. Seventeen patients in group II had stereopsis poorer than $400 \mathrm{~s}$ of arc. The mean ages at presentation and surgery were 4.9 and 6.3 years in group I and 2.7 and 3.0 in group II, respectively $(p=0.046,0.007)$. Posterior lenticonus was the most common cataract type in both groups $(p=0.20)$. Strabismus was more frequently associated with group II. Those who had no strabismus before and after cataract surgery were $66.7 \%$ in group I and $47.1 \%$ in group II $(p=0.02)$. Fifty-two per cent of patients in group I had a VA of 20/40 or better, but in group II, only one patient had a VA of $20 / 40(p<0.001)$. With a VA of $20 / 40$ or better as the reference level, the odds of having good stereopsis decreased significantly if VA in the eye with the cataract was less than 20/60 based on the multiple regression logistic analysis (OR 0.03, $p=0.0027$ ).

Conclusion: Stereopsis was better in children with later manifesting cataracts, in the absence of strabismus and in cases with a good postoperative VA. The postoperative VA was the most important factor affecting the outcome of stereopsis in children with unilateral pseudophakia.

Cataracts, which constitute a significant source of visual impairment in children, are responsible for nearly $10 \%$ of all visual loss in children worldwide. ${ }^{1}$ Unilateral opacities are more likely to cause permanent visual loss than bilateral opacities because of competition between the eyes. The management of a unilateral paediatric cataract remains challenging. ${ }^{2}$

Though paediatric cataract can have a various presentation and diverse visual outcome, prompt removal and aphakic correction by 6-8 weeks of life is necessary to prevent irreversible loss of vision, especially in unilateral dense congenital cases. In addition, normal neural development of binocular cortical cells requires clear retinal imaging during this critical period. ${ }^{3-5}$

Even with the advances in management of patients with unilateral cataract, the resulting binocularity, after treatment, has generally been poor. ${ }^{5-7}$ Fortunately, advances in paediatric cataract surgery have resulted in an increased use of intraocular lens implants (IOL) that are now commonly implanted in children's eyes for unilateral aphakic correction, at the time of the initial cataract extraction, even in infants under 6 months. ${ }^{8-12}$ The binocularity that results from the unilateral IOL implantation in childhood is thought to be better compared with the traditional correction with a contact lens. ${ }^{13}$ This is presumably because of the reduced interocular retinal image size disparity (aniseikonia) and the effects of the constant optical correction compared with contact lens-corrected aphakia. ${ }^{14}$

In our study, we retrospectively reviewed the outcome of stereopsis and the factors affecting the prognosis of stereopsis in children with unilateral pseudophakia. This study is the first analytical study on the factors affecting the prognosis of stereopsis in paediatric patients with unilateral pseudophakia.

\section{PATIENTS AND METHODS}

The charts of 38 patients who were diagnosed as having unilateral cataract and underwent cataract extraction with primary IOL implantation (in the bag or the sulcus) from 1997 to 2002 were retrospectively reviewed. Children who had a history of trauma, glaucoma and uveitis, and the presence of any significant organic lesion including the retina and optic nerve, those who had mental disabilities, and those who were uncooperative for stereopsis testing were excluded. The study was conducted at the Riley Hospital for Children, Indiana University, Indianapolis, Indiana, USA.

A comprehensive ophthalmology examination was performed with visual acuity (VA) assessment, ocular motility and alignment, biomicroscopy, cycloplegic retinoscopy, and indirect ophthalmoscopy for all patients before and after surgery. Keratometry $(\mathrm{K})$ readings and axial length measurements were obtained while the child was under general anaesthesia before surgery for calculating the IOL power. The power of the IOL was chosen based on calculation using the SRK II formula. The goal was to attain hyperopia based on the age and modify it based on the refractive error in the contralateral eye. ${ }^{15}$ An adhesive patch was applied over the phakic eye for $1 \mathrm{~h}$ /day per month of age until the child was 8 months old. This was started the second week following cataract surgery and converted to full time after 8 months of age. We followed the patching regimen recommended by the Infantile Aphakia Treatment Study to increase the binocular viewing time after the unilateral cataract surgery. ${ }^{10}$ However, this patching regimen was modified according to the compliance of the children. 
Table 1 Demographic data

\begin{tabular}{lccl}
\hline & Group $\mathbf{1}$ (good stereopsis) $\mathbf{N}=\mathbf{2 1}$ & Group II (poor stereopsis) $\mathbf{N}=\mathbf{1 7}$ & p Value \\
\hline Male (\%) & $9(42.9)$ & $8(47.1)$ & 0.7956 \\
Race (Caucacian) (\%) & $18(90.0)$ & $11(73.3)$ & 0.3670 \\
Age (years): mean (SD) & & & \\
At presentation & $4.9(3.6)$ & $2.7(2.5)$ & 0.0463 \\
At surgery & $6.3(4.6)$ & $3.0(2.5)$ & 0.0074 \\
At stereopsis & $9.6(4.5)$ & $5.6(1.8)$ & 0.0008 \\
\hline
\end{tabular}

Prism and cover testing were used to measure the preoperative and postoperative ocular alignment where possible. Krimsky testing or Hirschberg testing was also performed in patients with poor cooperation or fixation. Only deviations of 10 prism dioptres (PD) were considered for the presence of strabismus. The cataract types were classified into anterior polar, nuclear, posterior lenticonus, posterior polar, persistent fetal vasculature (PFV) and others based on the preoperative biomicroscopy under general anaesthesia.

The refractive values obtained under cycloplegic refraction were expressed as the spherical equivalent value (spherical power plus half of the cylindrical power in dioptres). Anisometropia was defined as a condition where the two eyes had an unequal refractive power of more than 2 dioptres.

Testing for stereopsis was performed using the Titmus stereotest plates (Stereo Optical Company, Chicago) by experienced examiners to exclude monocular clues and the results analysed quantitatively as arc seconds according to the patients' responses to the standard "circle" and "animal" targets.

The correlation between the stereoacuity and age at presentation, age at cataract surgery, cataract types, presence of strabismus, VA of both eyes and anisometropia were evaluated.

\section{STATISTICAL ANALYSIS}

Demographic characteristics such as age were compared between the two groups by a two-sample $t$ test for continuous variables and the $\chi^{2}$ and Fisher exact tests for categorical variables such as gender and race. The distributions of cataract types, types of strabismus and VA for each eye were compared between groups by the Fisher exact test. A p value of $<0.05$ was considered statistically significant. Raw numbers were reported when there was insufficient power for statistical evaluation.

Univariate logistic models for good stereopsis were used to screen variables for inclusion in a multiple regression logistic model. Variables that were significant in the univariate models at the 0.3 level were eligible for inclusion in the larger model. Backwards elimination was used to remove variables, until all remaining variables were significant at the 0.05 level. Two-way

Table 2 Distribution of cataract types

\begin{tabular}{lcccc}
\hline & Group I (\%) & & Group II (\%) & \\
\cline { 2 - 2 } & $\mathbf{N}=\mathbf{2 1}$ & & $\mathbf{N}=\mathbf{1 7}$ & p Value \\
\hline Posterior lenticonus & $14(66.7)$ & & $10(58.8)$ & 0.2008 \\
PFV & $1(4.8)$ & & $4(23.5)$ & \\
Nuclear & $1(4.8)$ & & $0(0.0)$ & \\
Anterior polar & $1(4.8)$ & & $0(0.0)$ & \\
Posterior polar & $0(0.0)$ & & $2(11.8)$ & \\
Lamella & $2(9.5)$ & & $0(0.0)$ & \\
Others & $2(9.5)$ & & $1(5.9)$ & \\
\hline
\end{tabular}

PFV, persistent fetal vasculature. interactions of the remaining variables were tested for statistical significance.

\section{RESULTS}

Thirty-eight patients were included in this study. Thirty-four patients with unilateral pseudophakia were eligible for this study, and four patients (three lamellar, one anterior polar) had minor lens opacification in the contralateral eye but were considered candidates for bilateral surgery. These patients were divided into two groups according to their stereoacuity. Group I consisted of 21 patients with good stereopsis of $400 \mathrm{~s}$ of arc or better. Group II included 17 patients with stereopsis worse than $400 \mathrm{~s}$ of arc (including no stereopsis). The $400 \mathrm{~s}$ of arc was considered a reference point between the good and poor stereopsis groups according to the Greenwald and Glaser classification. $^{13}$

Five patients $(24 \%)$ in group I had a stereoacuity better than $100 \mathrm{~s}$ of arc. Of the five patients who had excellent stereopsis ranging between 50 and $60 \mathrm{~s}$ of arc, four patients had posterior lenticonus, and one patient had an anterior polar type cataract. The remaining 12 patients (57\%) had a stereoacuity ranging between 100 and $200 \mathrm{sec}$ of arc, and four patients (19\%) in group I had $400 \mathrm{~s}$ of arc. On the other hand, only three patients in group II were able to pinch fly wings (3000 s), and the remaining 14 patients had no stereopsis at all. The mean age at stereopsis evaluation was 9.6 years (range 3.5 to 22 ) in group I and 5.6 years in group II (range 3.4 to 10 ).

Table 1 shows the demographic data for each group. The percentage of gender and race was similar in the two groups. The ages at presentation of the cataract and surgery were older for group I than group II. The mean ages at diagnosis and surgery were 4.9 and 6.3 years in group I, but 2.7 and 3.0 years in group II, respectively. These differences were statistically significant $(p=0.046,0.007)$. However, four patients in group I had undergone surgery under 6 months of age, and two patients among them had undergone very early surgery at 30 days for a nuclear cataract and at 40 days for a PFV and were included in the analysis. (table 1)

Table 2 shows the distribution of the types of cataracts. Posterior lenticonus was the most common type in both groups,

Table 3 Type of strabismus

\begin{tabular}{|c|c|c|c|}
\hline & Group I (\%) & Group II (\%) & \\
\hline Before/after cataract surgery & $\mathrm{N}=\mathbf{2 1}$ & $N=17$ & p Value \\
\hline Ortho/ortho & $14(66.7)$ & $8(47.1)$ & 0.0212 \\
\hline Ortho/XT & $0(0.0)$ & $3(17.7)$ & \\
\hline Ortho/ET & $1(4.8)$ & $1(5.9)$ & \\
\hline ET/ortho & $0(0.0)$ & $3(17.7)$ & \\
\hline ET/ET & $0(0.0)$ & $1(5.9)$ & \\
\hline $\mathrm{XT} /$ ortho & $5(23.8)$ & $1(5.9)$ & \\
\hline XT/XT & $1(4.8)$ & $0(0.0)$ & \\
\hline
\end{tabular}

$\mathrm{ET}$, esotropia; ortho, orthophoria; XT, exotropia. 
Table 4 Visual acuity of affected eye and anisometropia at the time of the stereopsis test

\begin{tabular}{lclll}
\hline & Group I & & Group II & \\
\cline { 2 - 2 } & $\mathbf{N}=\mathbf{2 1}$ & & $\mathbf{N}=\mathbf{1 7}$ & p Value \\
\hline $220 / 40$ & $11(52.4)$ & & $1(5.9)$ & 0.0003 \\
$\geqslant 20 / 60,<20 / 40$ & $5(23.8)$ & & $1(5.9)$ & \\
$>20 / 200,<20 / 60$ & $5(23.8)$ & & $7(41.2)$ & \\
$\leqslant 20 / 200$ & $0(0.0)$ & & $8(47.1)^{*}$ & \\
Anisometropia & $2(9.5)$ & $6(35.3)$ & 0.1066 \\
\hline
\end{tabular}

*One patient with visual acuity of poor Fix and Follow was included.

$67 \%$ in group I and $59 \%$ in group II. There was no statistically significant difference between the two groups with regard to the type of cataract $(p=0.20)$. The other categories included anterior polar, lamella, nuclear, PFV in group I and PFV posterior polar type in group II (table 2).

Strabismus was more frequently associated with poor stereopsis. Those who had no strabismus before and after cataract surgery were $66.7 \%$ in group I and $47.1 \%$ in group II. This difference was statistically significant $(p=0.02$; table 3$)$. The frequency of strabismus found before cataract surgery was similar in the two groups (29\% vs 30\%). However, in the six patients in group I found to have strabismus preoperatively, only exotropia was identified. On the other hand, four patients had esotropia, and only one patient had exotropia in group II. The postoperative strabismus were inevitably associated with patients in the poor stereopsis group ( $9 \%$ vs $30 \%)$. For the two patients in group I, one patient had $200 \mathrm{~s}$ of arc and had $12 \mathrm{PD}$ exophoria, and the other patient had 14 PD intermittent esodeviation with $400 \mathrm{~s}$ of arc. In group II, there were patients with esotropia and three with exotropia (table 3)

The postoperative best-corrected VA was better in group I patients where $52.4 \%$ of patients had a VA of $20 / 40$ or better $(p=0.0005)$, and all patients had a VA better than $20 / 200$ (range 20/80 to 20/20). On the other hand, in group II, only one patient had a VA of 20/40, and eight patients (47\%) had a VA less than 20/200 (table 4). The VA of the unaffected eyes were not significantly different, and this was the case in both groups $(p=0.72)$. The VA was the most important factor associated with good stereopsis by the univariate and the multiple regression logistic analysis. The patients with a VA of 20/40 or better (reference level) were likely to have good stereopsis (estimate $=2.4$, OR 11). The odds of good stereopsis significantly decreased if the VA of the eye with the cataract was less than 20/60 (table 5, OR 0.03, $p=0.0027$ ).

Anisometropia was more frequently observed in group II; however, this difference was not statistically significant $(p=0.11)$. Two patients $(9 \%)$ in Group I and six patients $(35 \%)$ in group II had anisometropia at the time of stereopsis testing (table 4).

\section{DISCUSSION}

Stereopsis is absent in almost all infants less than 3 months old. After this age, it rapidly develops to normal levels, which are reached by the sixth month of life. ${ }^{16}$ Normal neural development of binocular cortical cells requires clear retinal imaging during this critical period of visual development. ${ }^{15}$ Many studies have documented that the blurring of unilateral images, or aniseikonia, during the early period of visual development results in loss of binocular vision. ${ }^{17-19}$ Gregg and Parks ${ }^{20}$ suggested that the delayed timing of the surgical procedure, asymmetrical visual inputs (aniseikonia) and absence of
Table 5 Multiple regression logistic models

\begin{tabular}{lcll}
\hline Variable & Estimate (SE) & $\mathbf{p}$ Value & $\mathbf{O R}(\mathbf{9 5 \%} \mathbf{C l})$ \\
\hline Intercept & $2.40(1.04)$ & 0.0217 & \\
VA $(\geqslant 20 / 60$ to $<20 / 40)$ & $-0.79(1.51)$ & 0.6024 & $0.46(0.02$ to 8.83$)$ \\
VA $(<20 / 60)$ & $-3.50(1.17)$ & 0.0027 & $0.03(0.003$ to 0.30$)$ \\
\hline OR, odds ratio; VA, visual acuity. & &
\end{tabular}

binocular viewing time are presumably responsible for poor binocularity in these patients with unilateral congenital catatract. We thought that the morphology of the paediatric cataract types would be another factor affecting the binocular vision outcome. This is because the different types of cataract affect the timing of presentation and surgery. We excluded traumatic cataracts, since trauma is an aetiology rather than a morphological type.

Posterior lenticonus was the most common cataract type in both groups (67\% vs $59 \%$ ). This type of cataract represents the most common type of developmental cataract in a normal-sized eye. ${ }^{2}$ The visual prognosis, on average, is good, since the condition tends to progress slowly over time and is not as likely as fetal nuclear opacities to cause a severe deprivation amblyopia. ${ }^{2}$ However, in our patients with posterior lenticonus, stereopsis was quite variable from $50 \mathrm{~s}$ of arc to none. The posterior lenticonus in group II generally manifested earlier than in group I. We found that the prognosis for binocular vision in patients with posterior lenticonus was related to the age at presentation. For those with earlier manifestations, a poorer stereopsis outcome was likely.

The incidence of strabismus reported by various investigators since 1980 reveals a preoperative frequency of $33.3 \%$ and $78.1 \%$ postoperatively. ${ }^{21}$ In our study, noted strabismus in our pseudophakic patients preoperatively was similar in both group, $29 \%$ in group I and 30\% in group II. The proper use of IOL implantation reduced the incidence of strabismus. BenEzera and Cohen $^{22}$ noted that only $9 \%$ of children with unilateral pseudophakia developed strabismus, compared with $71 \%$ of children with aphakia treated with a contact lens. The reduced incidence of strabismus in children with unilateral pseudophakia compared with unilateral aphakia is due to the constancy of optical correction and the improved visual outcome in patients with pseudophakia. The noted postoperative strabismus was $9 \%$ in group I and 30\% in group II. The postoperative low frequency of associated strabismus in group I may represent the harmful effects of strabismus on stereopsis.

The absence of strabismus before and after cataract surgery indicates a good prognosis for the stereopsis outcome $(p=0.02)$.

Parks and $\mathrm{Hiles}^{23}$ found a strong correlation between the cataract type and risk for strabismus in 100\% of PFV cataracts and in $65 \%$ of nuclear cataracts, but only $48.4 \%$ with posterior lenticonus. The incidence of strabismus among different cataract types might be related to the visual outcome. It was difficult to assess the incidence according to the cataract type in our study because many patients with PFV, nuclear type, commonly associated with small eyes, did not undergo IOL implantation and were excluded from our study.

VA in paediatric patients with pseudophakia has been reported in several studies. In their series, Awner et al ${ }^{24}$ reported a VA of $20 / 40$ or better in $42 \%$ of an infantile group and in $67 \%$ of a traumatic group with unilateral pseudophakia. Zubcov et $a l^{25}$ reported a mean postoperative VA of 20/40 in the traumatic and developmental cataract group and a 20/100 VA in the congenital cataract group. In our study, the VA was $20 / 40$ or better in group I in $52 \%$ of patients and $5.9 \%$ of patients in 
group II. A VA better than 20/200 in group I was 100\% and only $53 \%$ in group II.

However, the relationship between VA and stereopsis remains somewhat controversial. But an interesting experiment showed well the relation of two functions such that a reduction in VA, with neutral filters over one eye, did not increase the stereoscopic threshold even if the VA was decreased to as low as 0.3. A further decrease in vision to 0.2 greatly increased the threshold, and with a decreased acuity of the covered eye to 0.1 , stereopsis was absent. ${ }^{16}$ Similarly, the chances of having good stereopsis decreased significantly if the VA of the affected eye was less than 20/60 in our study. We noted that the VA with unilateral pseudophakia had some association with stereoscopic acuity based upon the definite difference in VA of the affected eyes in comparisons between the two groups. However, there were 10 patients (47\%) in group I with VA less than 20/40 (range 20/80 to 20/50), and this suggests that stereoacuity, in unilateral paediatric cataract patients, associated with some degree of unavoidable amblyopia, has a better outcome than one might predict.

Anisometropia might be one of the several factors that could affect the stereoscopic acuity in patients with unilateral cataracts. This difference was not statistically significant $(p=0.1)$. It is certain that $0 \%$ aniseikonia is mandatory for normal stereopsis, but a low level of aniseikonia did not automatically mean that the patient's stereoacuity was good; therefore, factors other than the level of aniseikonia seem to influence stereoacuity. ${ }^{26}$

The limitations of this study include the small sample size, and only the Titmus fly test as a stereopsis test was performed.

In conclusion, the patients with good stereopsis were significantly older at presentation for cataract surgery, and they were not associated with strabismus before and after surgery. However, good postoperative VA of the affected eye was the most important factor associated with a good stereopsis prognosis in this study.

Acknowledgements: The authors thank S Ofner, biostatistician, for her help with the statistical analysis of this study.

Competing interests: None.

Ethics approval: Ethics approval was provided by IUPUI and Clarian Institutional Review Boards.

\section{REFERENCES}

1. American Academy of Ophthalmology. Basic and clinical science coursePediatric ophthalmology and strabismus 2005-2006. San Francisco: American Academy of Ophthalmology, 2005:271-83.
2. Wilson ME, Trivedi RH, Pandey SK. Pediatric cataract surgery; Technique,complication, management. Philadelphia: Lippincott William \& Wilkins, 2005:46-8

3. Birch EE, Stager DR. The critical period for surgical treatment for dense congenital unilateral cataract. Invest Ophthalmol Vis Sci 1996;37:1532-8.

4. Birch EE, Stager DR. Prevalence of good visual acuity following surgery for congenital unilateral cataract. Arch Ophthalmol 1988;106:40-3.

5. Wright KW, Matsumoto E, Edelman PM. Binocular fusion and stereopsis associated with early surgery. Arch Ophthalmol 1992;110:1607-9.

6. Brown SM, Archer S, Del Monte MA. Stereopsis and binocular vision after surgery for unilateral infantile cataract. J AAPOS 1999;3:109-13.

7. Biglan AW, Cheng KP, Davis JS, et al. Secondary IOL implantation after cataract surgery in children. Am J Ophthalmol 1997;123:224-34.

8. Neely DE, Plager DA, Borger SM, et al. Accuracy of intraocular lens calculations in infants and children undergoing cataract surgery. JAAPOS 2005;9:160-5.

9. Plager DA, Yang S, Neely DE, et al. Complications in the first year following cataract surgery with and without IOL in infants and older children. JAAPOS 2002;6:9-14

10. Lambert SR, Lynn M, Drew-Botsch C, et al. Intraocular lens implantation during infancy: perceptions of parents and the American Association for Pediatric Ophthalmology and Strabismus members. J AAPOS 2003; 7:400-5.

11. Lambert SR, Lynn M, Drew-Botsch C, et al. A comparison of grating visual acuity, strabismus, and reoperation outcomes among children with aphakia and pseudophakia after unilateral cataract surgery during the first six months of life. J AAPOS 2001;5:70-5.

12. Lambert SR, Lynn M, Drew-Botsch C, et al. Optotype acuity and re-operation rate after unilateral cataract surgery during the first 6 months of life with or without IOL implantation. Br J Ophthalmol 2004;88:1387-90.

13. Greenwald MJ, Glaser SR. Visual outcomes after surgery for unilateral cataract more than 2 years old: PC IOL implantation vs CL correction of aphakia. J AAPOS 1998;2:168-76

14. Katsumi 0, Miyanaga $Y$, Hirose T, et al. Binocular function in unilateral aphakia Ophthalmology 1988;95:1088-93.

15. Plager DA, Kipfer H, Sprunger DT, et al. Refractive change in pediatric pseudophakia J Cataract Refract Surg 2002;28:810-15.

16. Noorden GK. Binocular vision and ocular motility, theory and management of strabismus. 6th edn. St Louis: Mosby, 2002;25:298.

17. Wiesel TN, Hubel DH. Single-cell responses in striate cortex of kittens deprived of vision in one eye. J Neurophysiolol 1963;26:1003-17.

18. Hubel DH, Wiesel TN. The period of susceptibility to the physiological effects of unilateral eye closure in kittens. J Physiolol 1970;206:419-36.

19. von Noorden GK,Crawford MLJ.The effects of total unilateral occlusion versus lid closure on the visual system of infant monkeys. Invest Ophthalmol Vis Sci 1981;21:142-6.

20. Gregg FM, Parks MM. Stereopsis after congenital monocular cataract extraction. Am J Ophthalmol 1992;114:314-17.

21. Wilson ME, Trivedi RH, Hoxie JP, et al. Treatment outcomes of congenital monocular cataracts: the effects of surgical timing and patching compliance. J Pediatr Ophthalmol Strabismus 2003;40:323-9.

22. BenEzra D, Cohen E. Posterior capsulectomy in pediatric cataract surgery: the necessity of a choice. Ophthalmology 1997;104:2168-74.

23. Parks MM, Hiles DA. Management of infantile cataracts. Am J Ophthalmol 1967:63:10-19

24. Awner S, Buckely EG, DeVaro JM, et al. Unilateral pseudophakia in children under 4 years. J Pediatr Ophthalmol Strabismus 1996;33:230-6.

25. Zubcov AA, Stahl E, Rossillion B, et al. Stereopsis after primary in-the-bag posterio chamber implantation in children. J AAPOS 1999;3:227-33.

26. Katsumi 0, Miyanaga $Y$, Ogawa $T$, et al. Aniseikonia and stereoacuity in pseudophakic patients. Ophthalmology 1992;99:1270-7. 